\title{
Modeling of Shape Memory Alloys for Medical Design in Robotics
}

\author{
R. Leticia Corral-Bustamante ${ }^{*}$, Marco Antonio Flores Trevizo, Jose Nino Hernandez-Magdaleno
}

Department of Industrial and Mechatronics Engineering, Technological Institute of Cuauhtemoc City, Mexico

Copyright (C) 2015 by authors, all rights reserved. Authors agree that this article remains permanently open access under the terms of the Creative Commons Attribution License 4.0 International License

\begin{abstract}
This work is about the study of the advanced materials with shape memory alloys (SMAs) for the construction of a medical device for ablation of tumors via radio frequencies, which must be supported by a Cartesian robot of 3 degrees of freedom (RC3GL). The objective focuses on providing equipment to the medical sector to fill the role currently performed manually by the specialist of the state of Chihuahua, Mexico, in patients affected by cancer in organs such as liver, lung, kidney, prostate and breast. In the design of the medical device, it was necessary to control the temperature of transformation between the austenite and matensite phases to which the changes in shape of the SMA is produced in the range of $45^{\circ} \mathrm{C}$ to $50^{\circ} \mathrm{C}$. To fulfill the objective, two studies were conducted: i. statistical and ii. experimental by the annealing treatment of SMEs in determined temperature, time and rhythm of heating and cooling, measured by resistivity and dynamo-mechanical (DMTA) techniques that match those of other authors. From the results obtained, the nitinol $\left(\mathrm{Ni}_{\mathrm{wx}} \mathrm{Ti}_{\mathrm{yz}}\right)$ was selected as the alloy that meets the medical requirements for the successful design of the tumors remover. From the experimental tests for the thermal profile required in the nitinol tip during the ablation process of 8 minutes (modeling and previously simulated which are shown here), made with the medical device adapted to the RC3GL (patent pending), it can be concluded that, the objective of building the medical equipment for removing cancerous tumors in organs is met.
\end{abstract}

Keywords Shape Memory Alloy, Nitinol, Transformation Temperatures, Austenite-martensite, Annealing, Tumor Ablation Device

\section{Introduction}

This work is about the study of advanced materials called alloys with shape memory (SMAs), used in the design of equipment to remove cancerous tumors in human organs, which was implemented on a Cartesian robot with 3 degrees of freedom (RC3GL) [1] with the aim of supplying the manual function currently performed by the radiation oncologist on cancer patients in the State of Chihuahua, Mexico.

Two types of studies were performed: a) statistical and b) experimental, in order to determine the ideal material for medical application.

Statistical studies [2,3] allowed us to differentiate the nickel-titanium alloys of other alloys, allowing the nitinol position as the best candidate for the design of the remover, which led to experiments on the behavior of alloys of this material to find the exact alloy. The experimental tests were carried out by annealing treatments of nitinol measured with resistivity and DMTA techniques.

The objective of the statistical study focuses on knowing what alloys meet the requirement of changing its shape in the range of suitable temperatures to burn cancer cells $\left(45^{\circ} \mathrm{C}\right.$ $50^{\circ} \mathrm{C}$ ). Thus, temperatures of martensite-austenite transformation of SMAs represent the most important characteristic to measure for medical application proposed in this paper.

Once the appropriate SMA for ablation of tumors is obtained from the statistical study, the purpose of this work is focused on experimental trials for the behavior of $\mathrm{Ni}_{\mathrm{wx}} \mathrm{Ti}_{\mathrm{yz}}$ alloys, and then, build the tumors remover with the appropriate material.

Statistical tests include measures of dispersion, hypothesis testing, analysis of variance, Bonferroni multiple comparison test, fit and independence tests (Ji square test, contingency tables and independence test), data fitting by mathematical models of multiple regression to adjust curves and straights that include linear mathematical functions, nonlinear exponential parameters, quadratic, cubic and polynomial of degree $n[2,3]$.

The results of the hypothesis tests for 198 temperatures of start of martensitic and austenitic transformation of SMAs: Ms and As, respectively [4], indicate that there is significant difference between the mean transformation temperatures of the SMAs and temperature range for the medical application $\left(45^{\circ} \mathrm{C}-50^{\circ} \mathrm{C}\right)$. This allowed to lead the way to study the nitinol as a strong candidate in the design Remover.

The Analysis of Variance for 4 treatments with different 
transformation temperatures of nitinol alloys leads to the result that there is at least a mean of said treatments different of the others; and the Bonferroni multiple comparison test indicates that the differences between the mean lies at the end of martensitic and austenitic transformation $\left(\mathrm{M}_{\mathrm{f}}\right.$ and $\mathrm{A}_{\mathrm{f}}$, respectively) as expected.

Moreover, the Ji-square goodness of fit test for the transformation temperatures of 6 SMAs told us that the transformation temperatures $\left(\mathrm{M}_{\mathrm{s}}, \mathrm{M}_{\mathrm{f}}, \mathrm{A}_{\mathrm{s}}\right.$ and $\left.\mathrm{A}_{\mathrm{f}}\right)$ depend on the SMA as expected, setting a precedent for choosing a particular alloy.

From previous experimental tests made in the laboratory, similar to those obtained by other authors [5-7] it was found that the alloys closest to temperatures of $45^{\circ} \mathrm{C}-50^{\circ} \mathrm{C}$ are nitinol alloys.

Moreover, experimental tests were performed with nitinol alloys, given the mechanical properties of the alloy structure having the temperature range of interest. To design the tumors remover to burn cancer cells in human body organs, it is necessary to control the transformation temperatures to which such changes occur. This was accomplished by the annealing tratment, varying the annealing time and temperature, modifying in a controlled manner the temperature of transformation between the austenite and matensite phases.

From the annealing tests conducted at nitinol at certain temperatures and annealing times, with different load levels, results of transition temperatures are obtained which are important in the removal of tumors $\left(45^{\circ} \mathrm{C}-50^{\circ} \mathrm{C}\right)$, consistent with [8] .

From the hysteresis graphycs for nitinol transformation temperatures obtained here, in consistence with [7-15], it can be argued that there is evidence of transformation temperatures of nitinol to meet the expectations of the medical application.

Therefore, this work is going to influence on the medical filed through a proposed design for ablation medical device using nitinol. The transition used for medical application is presented here.

In this paper, it is also presented a graph of the thermal profile obtained on a electrode arm of nitinol for an ablation performed for 600 seconds [16,17].

\section{Nomenclature}

\begin{tabular}{|c|c|}
\hline A & frequency factor \\
\hline$C$ & number of columns \\
\hline$C M($ error $)$ & mean square error (MSE) \\
\hline$C_{b}$ & blood's specific heat $\left(\mathrm{J} \mathrm{kg}^{-1} \mathrm{~K}^{-1}\right), 3639[\mathrm{~J} \mathrm{~kg}-1 \mathrm{~K}-1]\left[\mathrm{J} \mathrm{kg}^{-1}{ }^{\circ} \mathrm{C}^{-1}\right]$ \\
\hline$C_{p}$ & heat capacity at constant pressure for the biological tissue $\left.\left.\left[\mathrm{J} \mathrm{kg}^{-1} \mathrm{~K}^{-1}\right]\right), 3600\left[\mathrm{~J} \mathrm{~kg}^{-1} \mathrm{~K}^{-1}\right)\right]$ \\
\hline$D e$ & activation energy \\
\hline$E$ & expected frequency \\
\hline$e$ & electric field intensity \\
\hline$F$ & statistic of test of one-factor ANOVA \\
\hline$H_{0}$ & null hypothesis \\
\hline$H_{1}$ & alternative hypothesis \\
\hline$k$ & number of samples (equal sample size); number of means of population being compared (unequal sample sizes) \\
\hline$n$ & sample size \\
\hline$n_{i}$ & number of values of the ith sample \\
\hline$n s_{x}^{\frac{2}{x}}$ & variance between samples \\
\hline$O$ & observed frequency \\
\hline$P$ & probability of accepting the null hypothesis $H_{0}\left(\chi^{2}\right.$ large $\rightarrow P$ small $)$ \\
\hline$Q_{\text {ext }}$ & source from spatial heating $\left[\mathrm{W} \mathrm{m}^{-3}\right]$ \\
\hline$Q_{j}$ & current source $\left(\mathrm{Am}^{-3}\right)$ \\
\hline$Q_{\text {met }}$ & source from metabolism $\left[\mathrm{W} \mathrm{m}_{-}{ }^{3}\right]$ \\
\hline$r$ & number of rows \\
\hline$s_{p}^{2}$ & variance within samples \\
\hline$s_{i}^{2}$ & variance of the values of the ith sample \\
\hline$t$ & temporal coordinate [s], critical value of $t$ of Student distribution ( test- $t$ ) \\
\hline$T$ & tissue temperature $\left[{ }^{\circ} \mathrm{C}\right]$ \\
\hline
\end{tabular}




\begin{tabular}{|c|c|}
\hline$T_{b}$ & arterial blood temperature $\left[{ }^{\circ} \mathrm{C}\right]$ \\
\hline$V$ & potential \\
\hline$X, X$ & sample mean \\
\hline $\bar{x}_{i}$ & mean of the values of the ith sample \\
\hline$Z$ & statistical of hypothesis testing \\
\hline$Z$ & cylindrical coordinate centered on the axis of the coaxial cable $\mathrm{Z}$ wave impedance in the dielectric of the cable \\
\hline \multicolumn{2}{|r|}{ Greek letters } \\
\hline$\delta_{t s}$ & time-scaling coefficient \\
\hline$\varepsilon_{r}$ & relative permittivity \\
\hline$\kappa$ & thermal conductivity $\left[\mathrm{W} \mathrm{m}^{-1}{ }^{\circ} \mathrm{C}^{-1}\right]$ \\
\hline$\mu$ & population mean \\
\hline$\omega_{b}$ & perfusion rate $\left[\mathrm{s}^{-1}\right], 0.0036\left[\mathrm{~s}^{-1}\right]$ \\
\hline$\phi$ & cylindrical coordinate centered on the axis of the coaxial cable \\
\hline$\rho$ & tissue density $\left[\mathrm{kg} \mathrm{m}-{ }^{3}\right]$ \\
\hline$\rho_{b}$ & blood's density $\left[\mathrm{kg} \mathrm{m}^{-3}\right]$ \\
\hline$\sigma, s$ & standard deviation \\
\hline$\sigma$ & electric conductivity $\left(\mathrm{S} \mathrm{m}^{-1}\right)$ \\
\hline$\chi^{2}$ & chi-square goodness of fit and independence test \\
\hline
\end{tabular}

\section{Shape Memory Alloys}

The shape memory alloys (SMA), are metalic alloys which after deformation return to its original shape after a temperature change.

These materials can be deformed and can recover its shape, so effects are called the thermal shape memory or elastic memory, these effects are due to a phase change of transformation thermoelastic martensitic.

These materials can be used for applications of force or movement, therefore were used in the medical device.

There are many alloys having shape memory and superelasticity, but only a few have been commercially developed, such as NiTi alloys, NiTi-X where $\mathrm{X}$ is a ternary element and $\mathrm{Cu}-\mathrm{Zn}-\mathrm{Al}$. Currently, 90\% of new applications are based on NiTi, NiTiCu and NiTiNb [18].

The $\mathrm{Ni} \mathrm{Ti}$ is capable of undergoing relatively high strains without that they be permanent, is also relatively stable to cyclical applications, and are resistant to corrosion by what is sometimes practiced in medical field.

In nitinol alloys can be substantially modified the transformation temperatures by small variations in the content of $\mathrm{Ti} / \mathrm{Ni}$.

\section{Medical Device}

\subsection{Medical Device Design in CAD Software}

First of all, is designed the medical device, according to the work area of the human organ, thus obtaining the design into its final form. After that, it is drawing in three-dimensional form (3D) using a software of drawing aided for computer, such as CAD software.

\subsection{Modeling of Medical Device through Software}

The medical device modeling and simulation was performed by using Comsol Multiphysics [19-21] software.

\subsection{Medical Device Materials Testing}

The test to selected materials was made After modeling, such as electrical resistance, deformation and recovery. with the aid of manufacturing tool was made the device.

\subsection{Development of Electronic Boards}

For physical evidence of medical device, in addition to manufacturing materials, the circuit which was designed into an electronic tablet was developed, which is generated through software as PCB Wizard [22].

\subsection{Electronic Tests}

With medical device and tablets manufactured in proper condition, the signal from the electronic circuit was captured, where the frequency and voltage is obtained, also the conduction test is accomplished in the medical device

\subsection{Adjusting Parameters}

With this, the results are compared with those obtained from the simulation software as well as the expected result 
shows if we have to make adjustments and determine what type and which corrections do we have to do and repeat the test.

\subsection{Design of Medical Device in Software CAD}

The medical device structure is composed of three different parts, with 2 metal and an insulating polymer. The parts are the trocar, insulating trocar, and tins.

On the other hand, the trocar is designed with stainless steel because it is for a surgical instrument, the trocar contain a insulating polymer to avoid contact with any organ or tissue in the body, because that way the circuit is shortened without being able to carry the radiofrequency to the affected part. In Figure 1 we can see the tips designed of nitinol whose benefits are excellent biocompatibility and no corrosion.

The device to tumor ablation was made in CAD software, such as Solid Works [23].

The trocar is designed with stainless steel and the dimensions are: $1.8288 \mathrm{~mm}$ diameter, $10 \mathrm{~mm}$ long, which is what protrudes from the insulation. In Figure 2 we can see the trocar done in Solid Works [23].

The isolation trocar aim is to protect human tissue in good condition of the Radio Frequency (RF) to be applied in the ablation, to avoid damage and not lose the power applied in the affected area, if there is contact between the trocar and healthy tissue would close the circuit before reaching the tumor and radiofrequency would have no effect to him.

Firstly, the insulation has to be between soft and hard to have a good mobility and improve the management of medical device; secondly, the biocompatibility is also important. Isolation can be made of different polymers could be manufactured as a catheter, materials such as silicone, nylon, polyurethane, and polyethylene terephthalate, perhaps can include thermoplastic elastomers.

In Figure 3 we can see the shape design of the polymer modeling Solid Works [23].

Four-tine radiofrequencies probe (four electrode arms) for tumor ablation are made of Nitinol (Ni-Ti) because this material have certain properties which are very useful in this application for its biocompatibility, as well as avoid corrosion and is a shape memory alloy, which with its curved shape caracteristic as in Figures 1 and 4 achieve wrap the tumor and covering the precise area for successful ablation, with less risk.

Four-tine radiofrequencies probe for tumor ablation has a curved shape, crescent, with an arc diameter of $15 \mathrm{~mm}$ and the diameter cylinder of $0.5334 \mathrm{~mm}$ of Nitinol material. Figure 4 shows one-tine radiofrequencies probe designed in the CAD Solid Works software [23] .

The device in Figure 1 is introduced in the RC3GL as we can see on Figure 5.

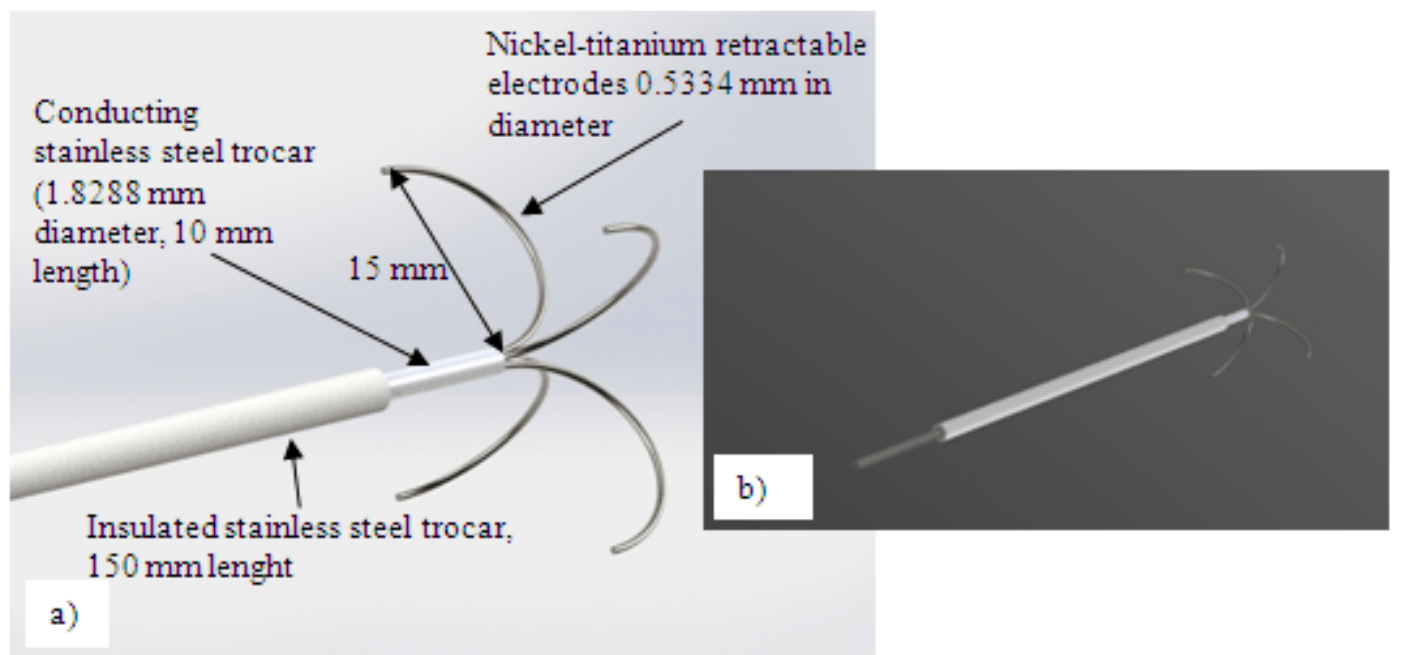

Figure 1. Design of the device proposed for tumor ablation. b) The structure of the fully deployed four-tine radiofrequencies probe like [16 ] for hepatic tumor ablation. 


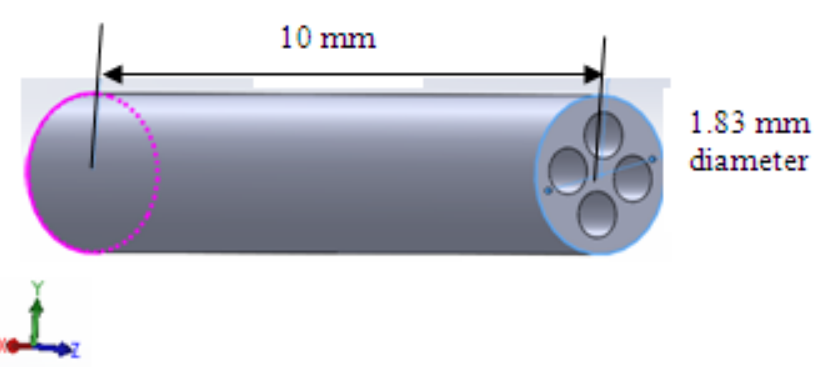

Figure 2. Dimensions of the trocar with the holes where four-tine probe (arms electrode) of nitinol will be inserted.

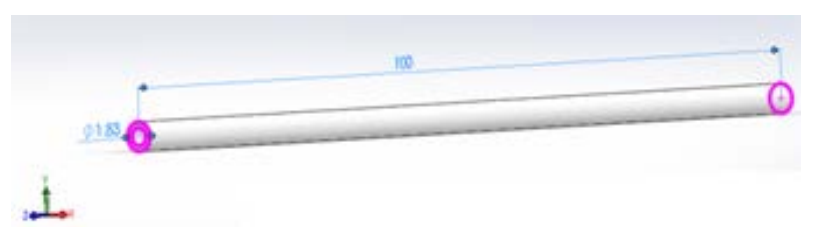

Figure 3. Model of isolation of the trocar.
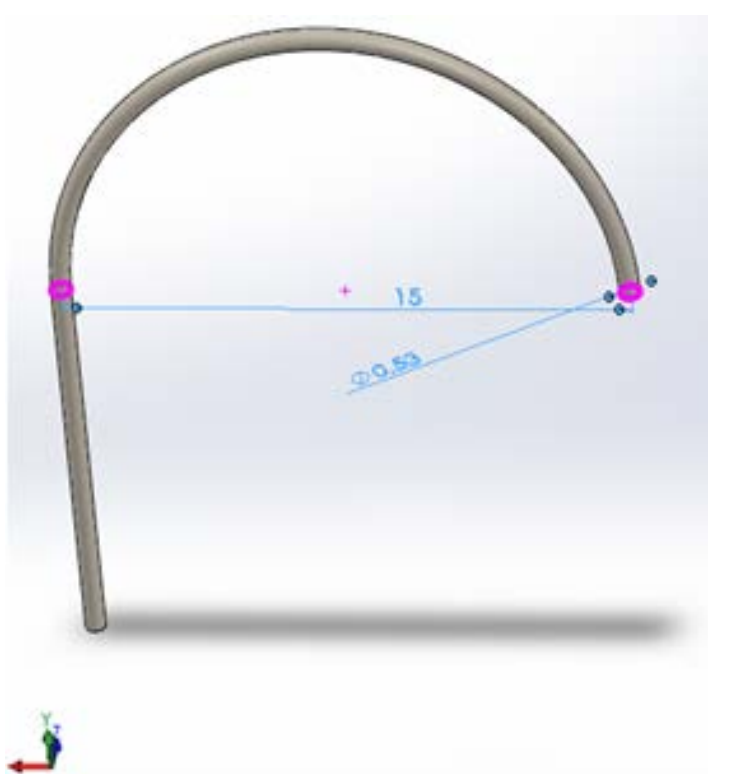

Figure 4. One-tine radiofrequencies probe for tumor ablation

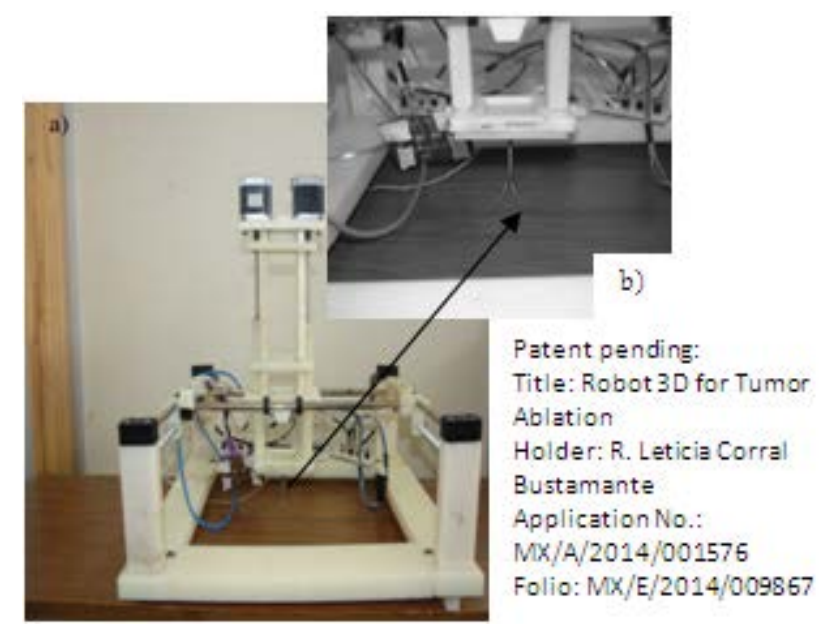

Figure 5. a) Cartesian Robot of 3 degrees of freedom (RC3GL) with b) tumor ablation device with four electrode arms of nitinol deployed from a stainless steel trocar.

\section{Modeling}

\subsection{Statistical Models}

The test statistics used are test- $t$ distributions (central limit theorem) and $Z$ for hypothesis testing, $F$ and $t$ for ANOVA and Bonferroni, $\chi^{2}$ for the independence test, respectively, de SMAs se describen a continuación.

$$
\begin{gathered}
t=\frac{\bar{x}-\mu}{s / \sqrt{n}} . \\
\mathrm{Z}=\frac{\bar{X}-\mu}{\sigma / \sqrt{n}} .
\end{gathered}
$$

$$
\begin{aligned}
& F=\frac{n s_{x}^{2}}{s_{p}^{2}} \\
& =\frac{\sum n_{i}\left(\overline{x_{i}}-\bar{x}\right)^{2} / k-1}{\sum\left(n_{i}-1\right) s_{i}^{2} / \sum\left(n_{i}-1\right)} .
\end{aligned}
$$

$t_{\text {Calculated Bonferroni }}$

$$
\begin{aligned}
& =\frac{\bar{x}_{1}-\bar{x}_{4}}{\sqrt{C M(\text { error }) \cdot\left(1 / n_{1}+1 / n_{4}\right)} .} \\
& \chi^{2}=\sum \frac{(O-E)^{2}}{E}, \\
& \text { degree of freedom }=(r-1)(c-1) .
\end{aligned}
$$

\subsection{Multiple Regression Models}

The models of curves fit to the data of SMAs are described below.

Model function $a t+b \exp (x)$, (values of $a$ and $b$ that minimize the least-squares error)

$$
\begin{aligned}
& L S E=39.4991623216999 x \\
& -0.10848873867082 \exp (x) .
\end{aligned}
$$

Polynomial of degree 3, 4, 5 and 20, respectively, through experimental data obtained

$$
\begin{aligned}
& P D 3=152.0833+20.1814 x \\
& -8.1793 x^{2}+0.4955 . \\
& P D 4=237.8971-112.0699 x \\
& +53.4276 x^{2}-10.42 x^{3}+0.64 x^{4} . \\
& P D 5=69.39+209.15 x-151.97 x^{2} \\
& +46.98 x^{3}-6.57 x^{4}+0.333 x^{5} .
\end{aligned}
$$




$$
\begin{aligned}
& P D 20=8.8 \cdot 10^{-14} x+3.4 \cdot 10^{-13} x^{2} \\
& +1.3 \cdot 10^{-12} x^{3}+\ldots+8.6 \cdot 10^{-7} x^{16} \\
& -8.6 \cdot 10^{-7} x^{17}+\ldots-\ldots+9.8 \cdot 10^{-10} x^{20} .
\end{aligned}
$$

The model function $a x+\exp (b x)$, which is nonlinear in the parameters $a$ and $b$.

$$
\begin{aligned}
& M F N P=28.6485428293575 x \\
& +\exp (-0.0456903740665516 x) .
\end{aligned}
$$

\subsection{Bioheat Equation}

To model the operation of the device to remove tumors was used the bioheat equation that governs conduction heat transfer with the approach of Penne [24,19-21] to represent the heat from metabolism and blood perfusion

$$
\begin{aligned}
& \delta_{t s} \rho C_{p} \frac{\partial T}{\partial t}+\nabla \cdot(-\kappa \nabla T) \\
& =\rho_{b} C_{b} \omega_{b}\left(T_{b}-T\right)+Q_{m e t}+Q_{e x t} .
\end{aligned}
$$

Where, $\nabla=\hat{\rho} \frac{\partial}{\partial t}+\frac{\phi}{\rho} \frac{\partial}{\partial \phi}+\hat{z} \frac{\partial}{\partial z}$

and,

$$
\begin{aligned}
& -\nabla \cdot\left(\sigma \nabla V-\mathbf{J}^{e}\right)=Q_{j} \stackrel{\mathbf{J}^{e}=Q_{j}=0}{\rightarrow} \\
& -\nabla \cdot(\sigma \nabla V)=0
\end{aligned}
$$

Modeling of the robot functions was performed by the Comsol Multiphysics software [19-21], which makes use of the heat transfer capacity [24-30] to simulate therapy and the removal of damaged tissue cells. The human tissue is modeled as a cylindrical geometry to which a conductive heat is applied to burn the cancer cells. The module of heat transfer in biological tissues uses the bioheat transfer interface of Comsol and plays an important role in technology for medical purposes.

The terms on the left-hand side of (12) belong to the model of biological tissue, while the terms on the right-hand side provide the bioheat model [25]. Tumor ablation involves passing of four electrodes at a given temperature through the affected tissue. The method involves inserting a tube in which electrical current flows through four electrodes leaving a plunger, to the well localized cancerous tissue. Radio frequencies are used to heat these electrodes due to heat transfer $[17,19-21,24]$ up to a temperature between 45 and $50^{\circ} \mathrm{C}$ in the tissue.

This method serves to increase the cell temperature above $45-50^{\circ} \mathrm{C}$, resulting in protein denaturation with coagulation that is the ultimate cause of cell death and tissue necrosis. RF tumor ablation could be implemented in patients with liver tumors [16,31], kidney, lung [32], prostate and breast, among others. Currently, a radiation oncologist [32-37] performs this function by hand as far as information is available in the State of Chihuahua.

The probe is a needle (main bar) and four electrode arms as shown in Figure 1. The needle is electrically isolated, except near the electrode arms. An electric current through the probe creates an electric field in the tissue. The field is the strongest in the immediate vicinity of the probe and generates resistive heating, which dominates around the arms of the probe electrode due to the strong electric field.

The geometry include damaged tissue, an artery near the tumor and the medical device with trocar, insulator and the structure of the fully deployed four-tine radiofrequencies probe of nitinol (see Figure 6 of Comsol 4.4).

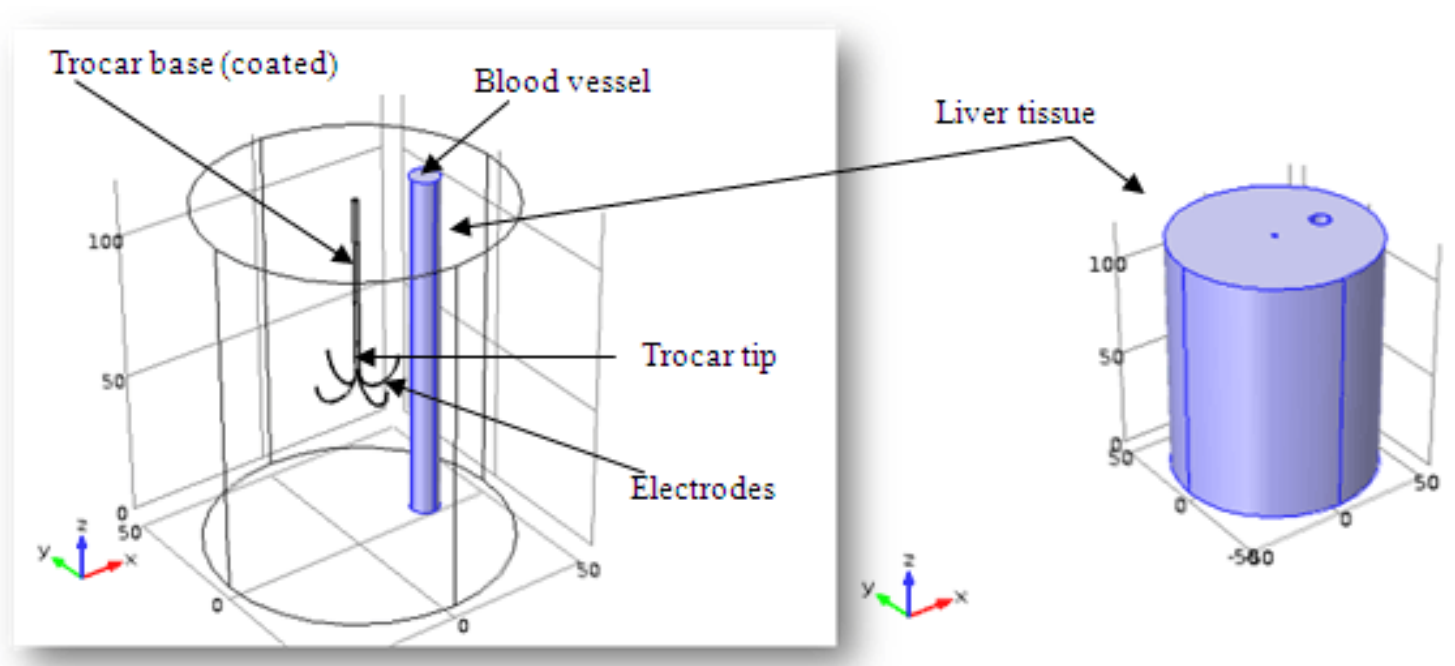

Figure 6. Geometry of organ tissue for ablation, with artery near the tumor. Courtesy of COMSOL Multiphysics ${ }^{\circledR}$ Release Highlights Version 4.4 https://www.comsol.com/release/4.4 
For the Geometry of Figure 6 parameters or material properties are added (see Table 1).

Table 1. Parameters assigned to the different parts of the tumor ablation geometry.

\begin{tabular}{|c|c|c|c|c|}
\hline Parameter & Trocar & $\begin{array}{c}\text { Blood } \\
\text { vessel }\end{array}$ & $\begin{array}{c}\text { Hepatic } \\
\text { tissue }\end{array}$ & Electrods \\
\hline$\rho$ & $\checkmark$ & $\checkmark$ & $\checkmark$ & $\checkmark$ \\
\hline$\kappa$ & $\checkmark$ & $\checkmark$ & $\checkmark$ & $\checkmark$ \\
\hline$A$ & $\checkmark$ & & $\checkmark$ & $\checkmark$ \\
\hline$D e$ & $\checkmark$ & & $\checkmark$ & $\checkmark$ \\
\hline$C_{p}$ & $\checkmark$ & $\checkmark$ & $\checkmark$ & $\checkmark$ \\
\hline$\sigma$ & $\checkmark$ & $\checkmark$ & $\checkmark$ & $\checkmark$ \\
\hline$\varepsilon_{r}$ & $\checkmark$ & $\checkmark$ & $\checkmark$ & $\checkmark$ \\
\hline
\end{tabular}

The initial parameters are values of starting voltage, temperature of arterial blood, initial temperature, blood density, rate of perfusion of blood, blood heat capacity (parameters that may vary through the time).

The expected results from the experiments are simulation results for radiofrequency ablation of tumor in organs like the liver, in an estimated time of 8-10 minutes.

In Figure 7 electric potential or voltage applied to the affected area is observed. It can be seen how the electric potential is distributed through the tissue, when the potential has advanced some distance from tissue, increases its impedance.

Remember that the electric potential is introduced in the form of radio frequency of $500 \mathrm{kHz}$ and a voltage of 30 volts average. The human liver has an impedance between 50 and 60 Ohms and a power of $16 \mathrm{~W}$, but when ablation progresses this impedance is likely to increase.

Figure 8 shows the temperature distribution which is caused by tumor ablation where cells react to the potential induced through radiofrequency, obtaining a movement or vibration between them, which generates enough heat as shows the graph.

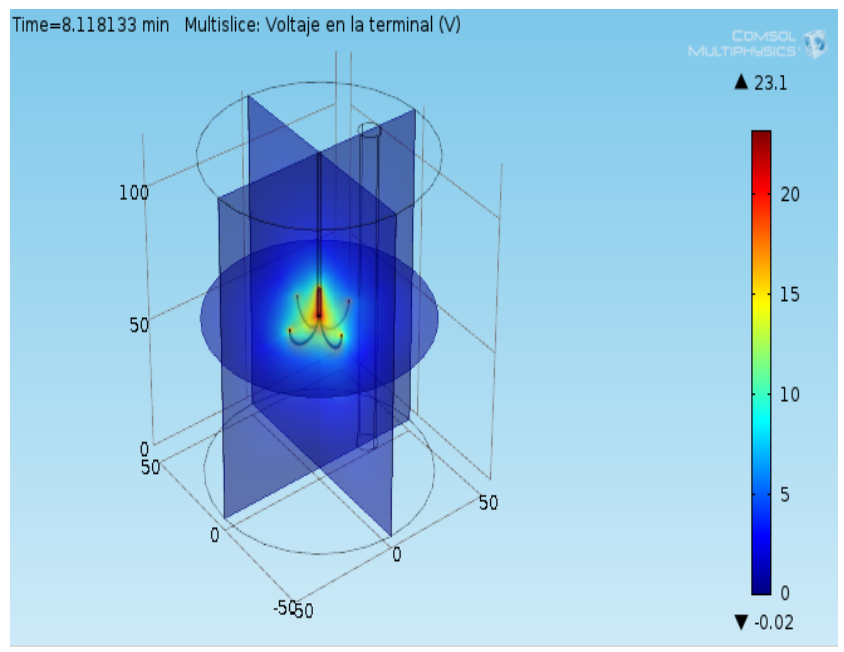

Figure 7. Electric potential in the medical device [19].

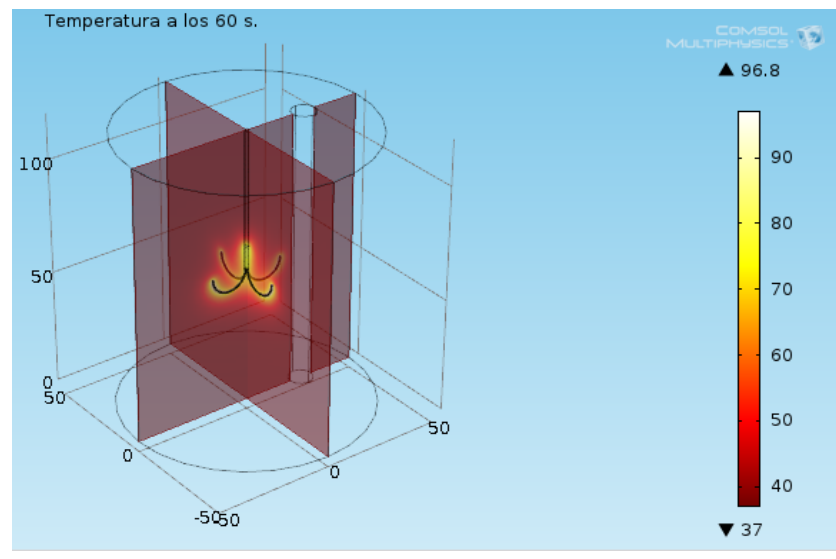

Figure 8. Thermal profile in tumor ablation [19].

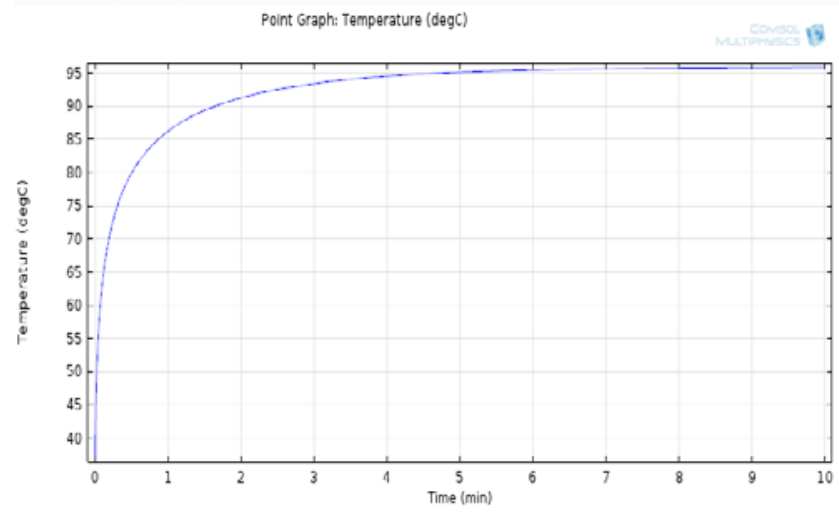

Figure 9. Distribution of temperature in one of the electrode arms of nitinol [19]

The temperature starts at 37 degrees Celsius in Figure 8, ie, body temperature, so the outer liver tissue is maintained at that value, and the maximum value is 100 degrees Celsius; this value is the maximum to ensure successful ablation process. Since at this temperature it is a necrotic tissue; ablation starts at 55 degrees Celsius.

Four tines of electrode have the highest temperature because of the increased electric potential there.

The necrotic tissue is when the affected area is already at a temperature of 100 degrees Celsius, this is sufficient for ablation.

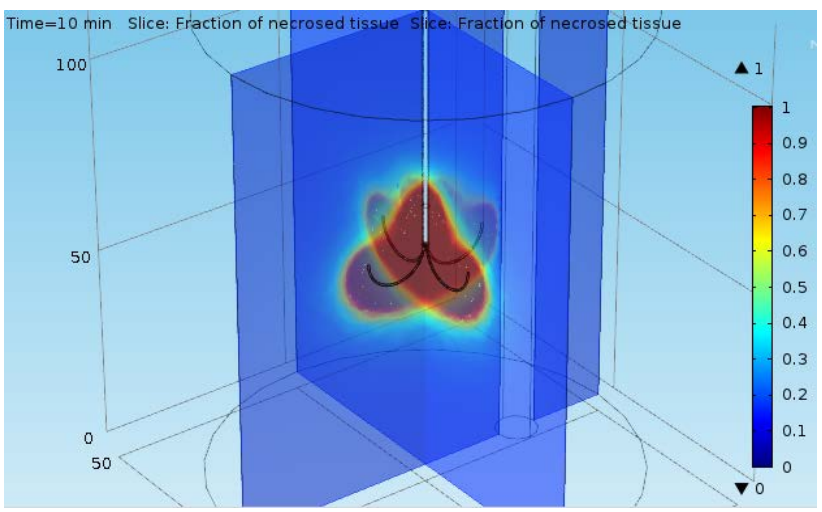

Figure 10. Graph of necrotic tissue [19] 
The results expected from experimentation must meet the simulation presented by the graph in Figure 9 for the thermal profile in one of the electrode arms of nitinol during the tumor ablation process. At this point, the liver tissue becomes necrotic as in Figure 10.

\section{Electronic Circuit Design}

The development of electronics circuits is based in express the designs have been simulated earlier in a phenolic plates made of copper on one side, where the tracks (conduction lines) are adapted to a given space to reach the electronics pieces (all pins).

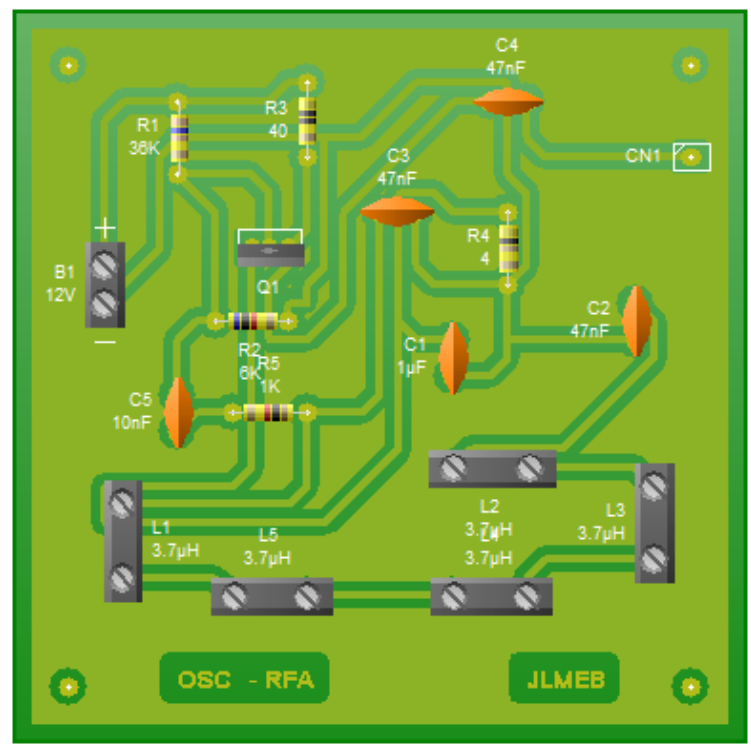

Figure 11. PCB Design Oscilador en vista mundo real.

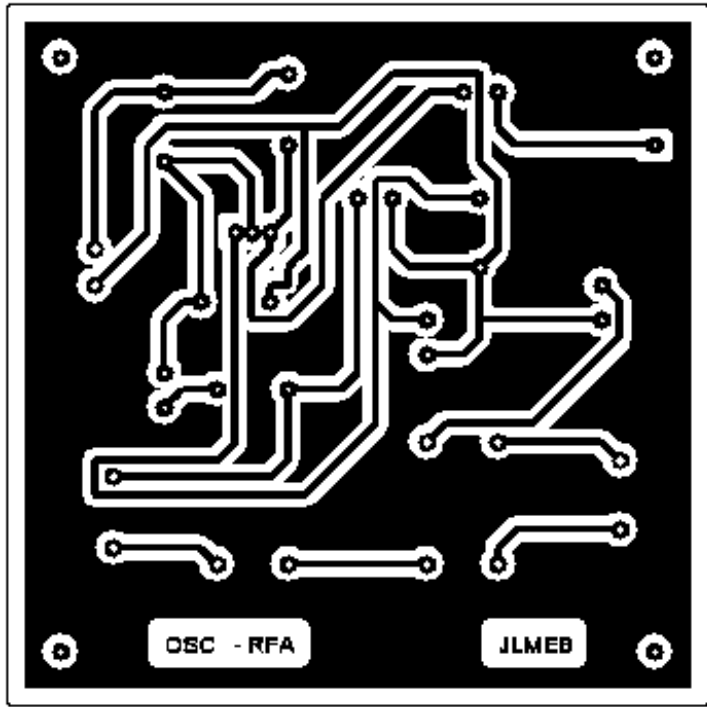

Figure 12. PCB Design Oscilador vista para placa fenólica.

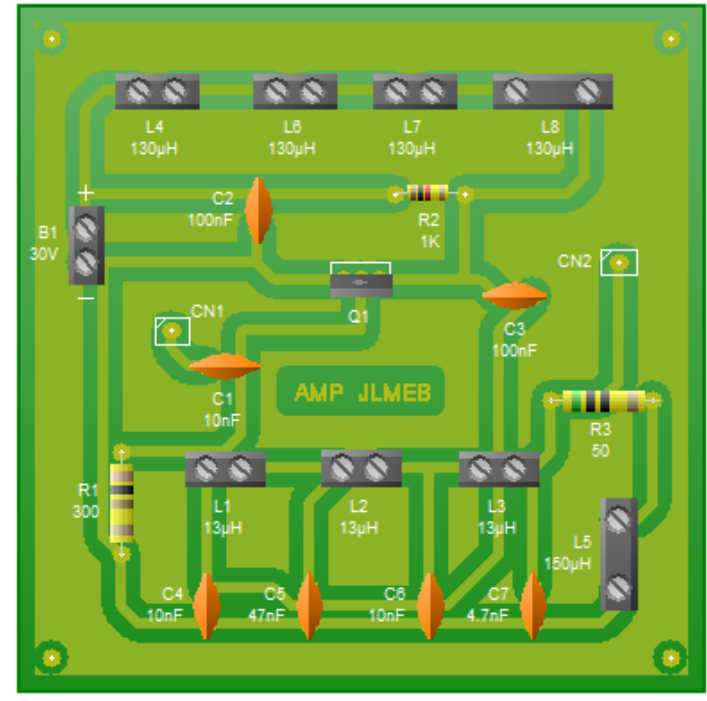

Figure 13. Real view of PCB Design Amplificador.

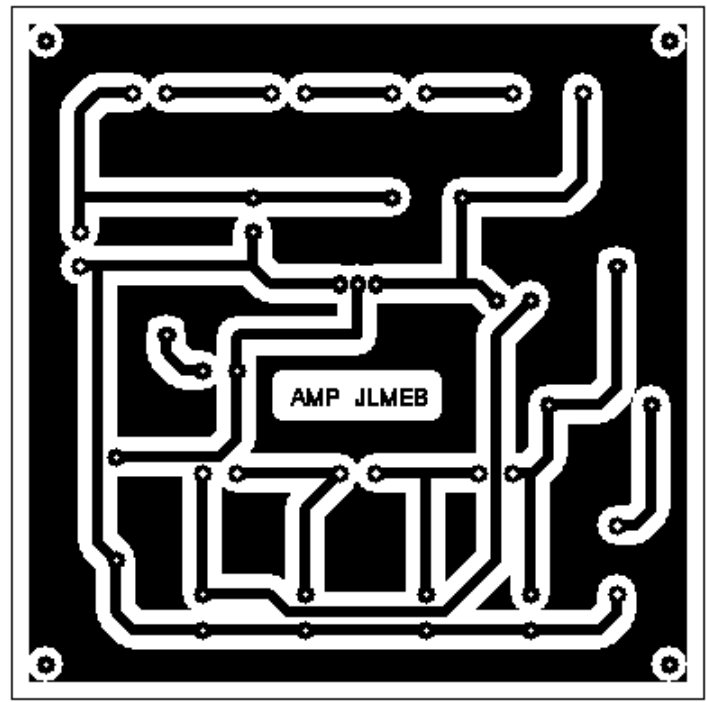

Figure 14. PCB Design Amplificador for phenolic board.

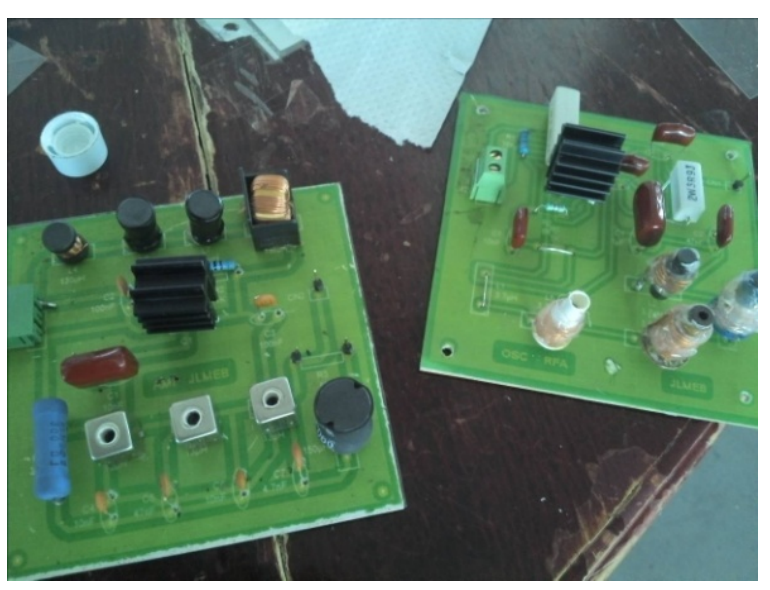

Figure 15. Physical circuits in PCB. 


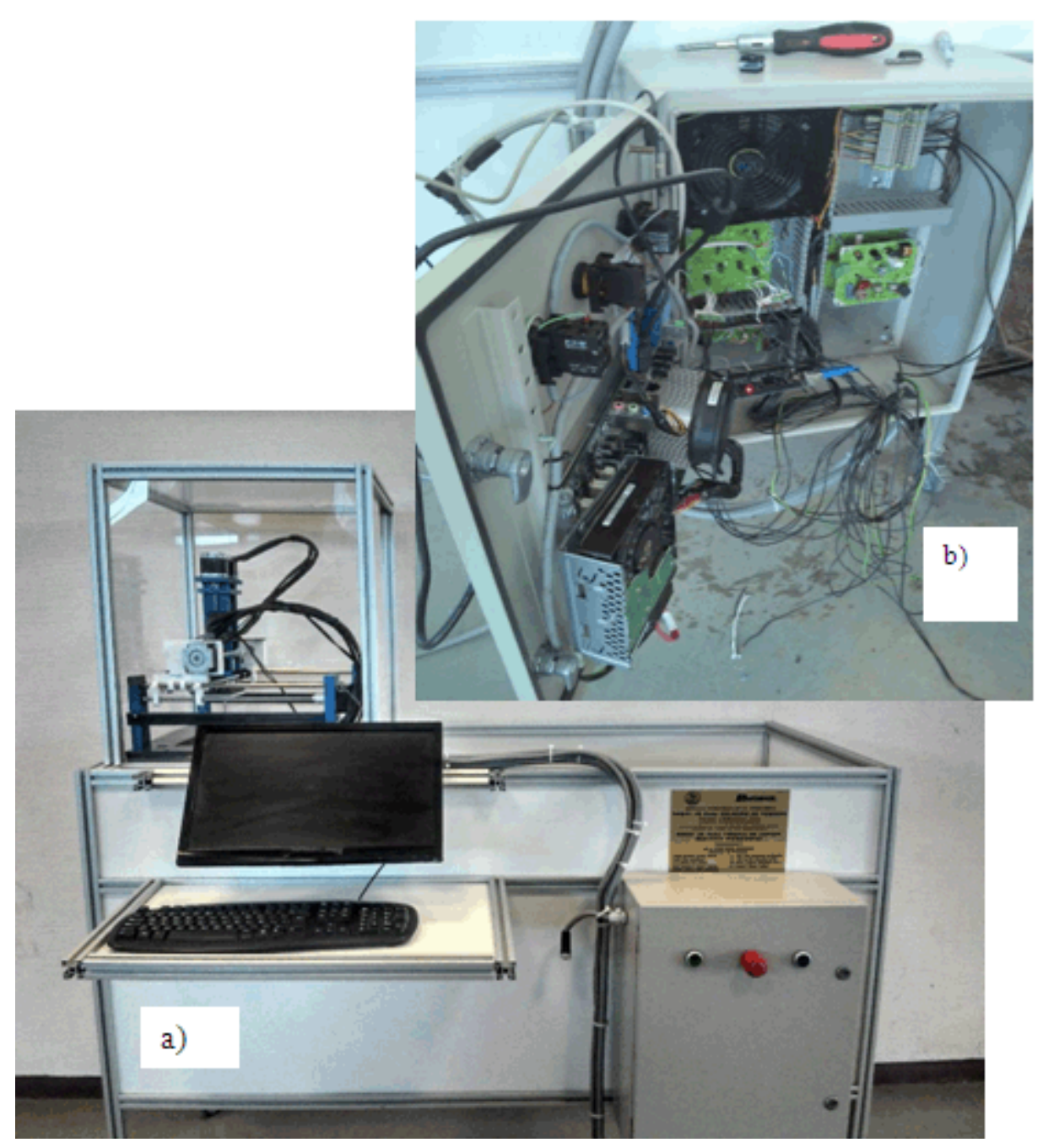

Figure 16. a) Cabinet finished and mounted on mobile unit. b) Process of connection.

This is converted to PCB Wizard program format to capture it in a physical world and not simulation.

Within the program you can generate different views to print, of which two are important, the view for phenolic plate and the view of the real world. Figures 11 and 12 show the circuit in PCB software

The amplifier circuit in Livewire was developed for creating electronic circuits on phenolic board or ironed which consists in express by means of heat the prints on transparent paper printed with laser, so the blade is magnetized and is easier pass the toner to the phenolic plate (see Figs. 13 and 14).

Figure 15 shows how the circuits were expressed in phenolic plate phisically.

Once the mechanical and electronic design finished, we proceeded to design wiring diagrams and electrical cabinet for 3D Robot for tumor ablation (see Figure 16 a)).

Parts of the system for ablation, such as oscillator, amplifier, power, and control means were placed, the SolidWorks software was used on its extension electrical.

Figure $16 \mathrm{~b}$ ) shows the robot design and electrical cabinet as well as a image where the connection process shown.

\section{Results and Discussion}

The results of the statistical and experimental study are presented in this section. Behavior relevant results of nitinol for use in the design and construction of a device for ablation of tumors are also discussed.

Two types of tests to determine the behavior of advanced materials with shape memory alloys were performed, in order to find the alloy that meets the medical requirements for the design of a device to remove cancerous tumors in organs such as liver, lung, kidney, prostate and breast. This device must be supported by a Cartesian robot with 3 degrees of freedom (RC3GL) to fulfill the function of removal.

The main features to observe are the transformation temperatures of austenite-martensite that present the SMAs. In this regard, the design of the remover requires that the SMA being heated by an annealing process, reach the transition temperature in the range of $45^{\circ} \mathrm{C}$ to $50^{\circ} \mathrm{C}$, changing its shape.

The tumor ablation device was constructed with four sharply curved tubular needles which are deployed from a stainless steel trocar to penetrate and burn the damaged 
tissue in only one session of eight minutes, as in $[16,17]$.

First of all, statistical tests to a sample of 198 SMAs were performed to detect the temperature range of transition suitable for the design of the remover. This study allows to justifiy the precision with which it must be chosen the alloy in the medical application (Figs. 17 and 18).

Secondly, and based on the results showed in the statistical study, experimental tests by the annealing treatment and the loads applied to such temperatures were performed, measured by resistivity and DMTA techniques consistent with [7].

As a conclusion, with all these data and properties, the design of medical device with the $\mathrm{Ni}_{\mathrm{wx}} \mathrm{Ti}_{\mathrm{yz}}$ alloy is more precise and reliable under the actual service conditions (see Figures 19-22).

\subsection{Statistical Tests}

Statistical tests are important in this work because they allow to verify that the alternative hypothesis $H_{1}$ is true over the null hypothesis $H_{0}$. This means that, from a representative sample of SMAs, we are confident of what type of alloy meets the requirements of transition temperatures for the intended medical application. Hypotheses are here

$$
\begin{aligned}
& H_{0}=45^{\circ} \mathrm{C}-50^{\circ} \mathrm{C} \\
& H_{1} \neq 45^{\circ} \mathrm{C}-50^{\circ} \mathrm{C}
\end{aligned}
$$

Statistical tests include measures of dispersion, hypothesis testing, analysis of variance, Bonferroni multiple comparison test, Ji-square tests (contingency tables and test of independence), data fitting by mutiple regression mathematical models.

A simple random sample of 198 starting temperatures of martensitic and austenitic transformation of SMAs was taken from various laboratory tests previously performed, which are consistent with results from several sources in [4], Ms and As, respectively (with standard deviation of $248.38475^{\circ} \mathrm{C}$ and an mean of $127.416867^{\circ} \mathrm{C}$ ), of a population that follows an approximated normal distribution, in order to know if the mean temperature is different from $45^{\circ} \mathrm{C}-50^{\circ} \mathrm{C}$ which is the target range for the medical application.

A confidence level of $99 \%$ was used, for which the probability of committing a type 1 error (rejecting the null hypothesis when it is true) is 0.01 (significance level).

Form the analysis of the hypothesis test performed, the alternative hypothesis is supported about that the temperatures of the Ms and As of the SMAs sample are different from $45^{\circ} \mathrm{C}-50^{\circ} \mathrm{C}$, which leads us to conclude, with $99 \%$ confidence, that only those SMAs whose transformation temperatures oscillate between $45^{\circ} \mathrm{C}-50^{\circ} \mathrm{C}$ which is the ideal temperature to burn or kill cancer cells, are important. This is the reason why it was decided to use nitinol as the material that has the requisites of temperature transformation.
4 different data of transformation temperatures of Nitinol alloys (treatments) were taken and One-Factor ANOVA was performed. The results allow arguing that there is at least one mean of temperatures which differs from the others; and the Bonferroni multiple comparison tests indicates that $t_{M_{f}-A_{f}}=-3.4814<t_{c r i t i c}=-3.2849$

$$
\therefore \mu_{M_{f}} \neq \mu_{A_{f}} \text {, }
$$

which implies that $\mathrm{M}_{\mathrm{f}}$ is different from $\mathrm{A}_{\mathrm{f}}$ as expected.

In Table 2, data of transformation temperatures of 6 SMAs tested in our laboratory for metallurgy, approximately consistent with other authors [5-7] are dispayed, to which were applied a chi square test to prove that the row variables are dependent on the column variables.

With a confidence level of $99 \%$ and 15 degrees of freedom of chi-squared tables the critical value is compared against the value of Ji calculated:

$\chi_{\text {calculated }}^{2}=85.17>\chi_{\text {critical }}^{2}=30.58$, meaning that the row variables are dependent on the column variables, i.e., the groups (transformation temperatures $\mathrm{M}_{\mathrm{s}}, \mathrm{M}_{\mathrm{f}}, \mathrm{A}_{\mathrm{s}}$ and $\mathrm{A}_{\mathrm{f}}$ ) depend on the SMA to which they belong, as expected. This conclusion is reinforced by the small value of $P$.

As it can be seen, this statistical study allows us to be strict in choosing the SMA for medical application.

In Figure 17 a) - f) the graphs of transformation temperatures of 6 SMAs similar to those obtained by other authors [5-7] are displayed. At glance it is observed that the alloys closest to the temperatures of $45^{\circ} \mathrm{C}-50^{\circ} \mathrm{C}$ are contained in Figure 17 a), d) and e), that is to $\mathrm{Ni}_{49} \mathrm{Ti}_{51}$, Ti-Ni-Cu and Nitinol alloys, respectively.

In this regard, Figure 18 a) - d), led us to confirm that, from Figure $17 \mathrm{f}$ ), in the range of the medical application $\left(45^{\circ} \mathrm{C}-50^{\circ} \mathrm{C}\right)$ the important transition temperatures are for Ti-Ni-Cu and nitinol alloys (Figure $17 \mathrm{~d}$ ) and e)). Also, for a good range of $45^{\circ} \mathrm{C}-60^{\circ} \mathrm{C}$ the two previews are important and $\mathrm{Ni}_{49} \mathrm{Ti}_{51}$ starts to make inroads (see Figure $17 \mathrm{a}$ )).

Figure 18 shows characteristic temperatures of transformation of SMAs and graphs of statistical models of fitting of temperature data that show the trend behaviors for choose the right materials to remove tumors [5-7].

In Figure $18 \mathrm{c}$ ) and d) it is observed that the curves that best fit the data of $45^{\circ} \mathrm{C}-50^{\circ} \mathrm{C}$ are the polynomials of degree 3 and 4 (PD3 and PD4 of (7) and (8)), also least-square error: $a t+b \exp (x), \quad(6), \quad$ and model function $a x+\exp (b x), \quad(11)[2,3]$. The polynomial of degree 5 (PD5 of (9)) appears to a lesser degree.

Table 2. Transformation temperatures of some SMAs obtained previously in laboratory tests.

\begin{tabular}{|c|c|c|c|c|}
\hline Alloy/Temperature & $\mathrm{M} \mathrm{s}$ & $\mathrm{M} \mathrm{f}$ & $\mathrm{A} \mathrm{s}$ & $\mathrm{A} \mathrm{f}$ \\
\hline $\mathrm{Ni}_{49}-\mathrm{Ti}_{51}$ & 13 & -4 & 28 & 46 \\
\hline $\mathrm{Cu}-\mathrm{Al}-\mathrm{Cd}$ & 259 & 193 & 309 & 397 \\
\hline $\mathrm{CuAlAg}$ alloy 1 & 273 & 182 & 292 & 414 \\
\hline CuAlAg alloy 2 & 205 & 82.5 & 257 & 429 \\
\hline TiNiCu & 42 & 33 & 53 & 62 \\
\hline Other nitinol alloys & 35 & 21 & 55 & 63 \\
\hline
\end{tabular}



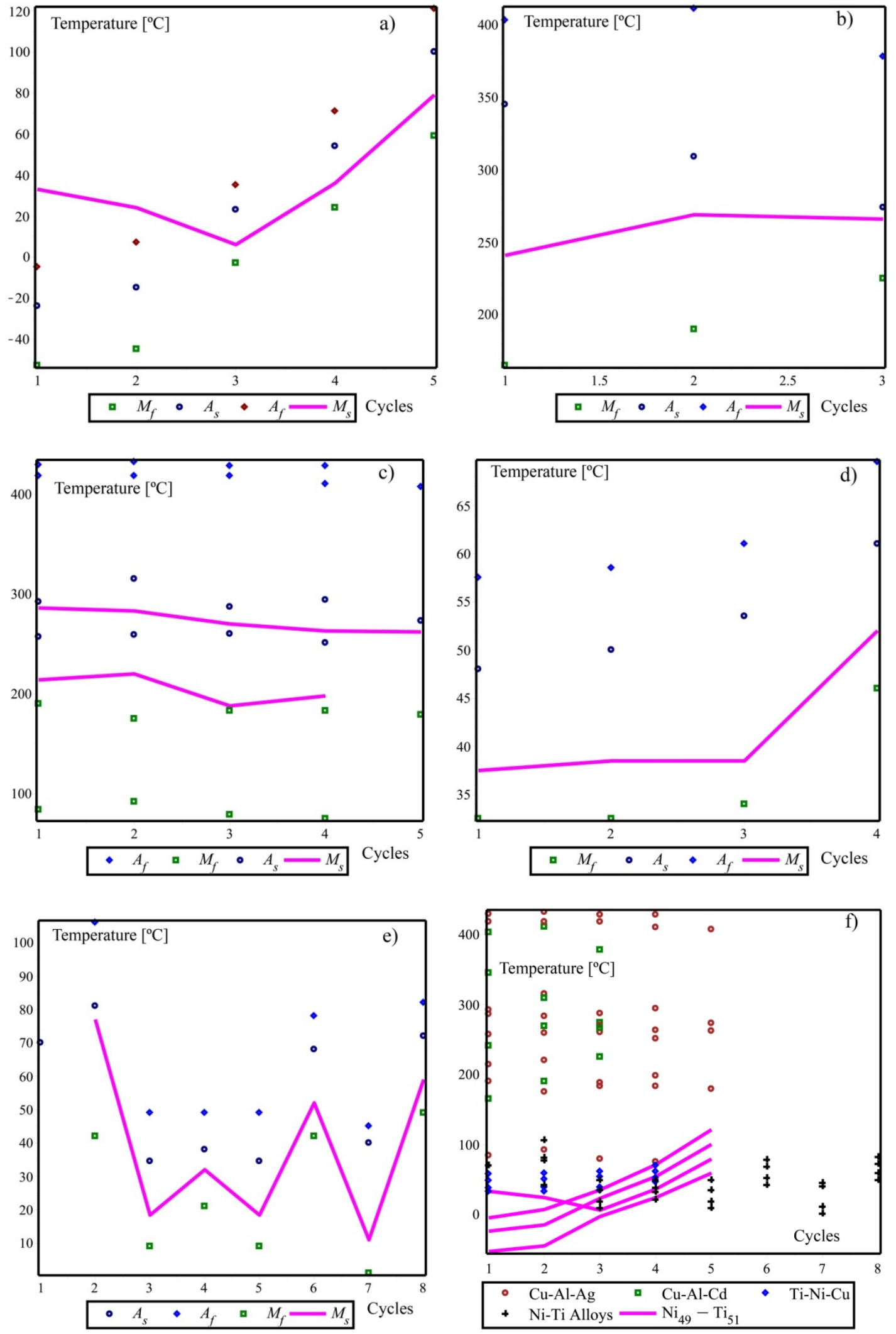

Figure 17. Characteristic temperatures of the austenite-martensite transformation as a function of cycling of shape memory alloys ( $\mathrm{SMAs}$ : a) $\left.\mathrm{Ni}_{49} \mathrm{Ti}_{51}, \mathrm{~b}\right)$ Cu-Al-Cd alloys, c) Cu-Al-Ag alloys, d) Ti-Ni-Cu, e) Nitinol alloys and f) all a)-e) SMAs. 

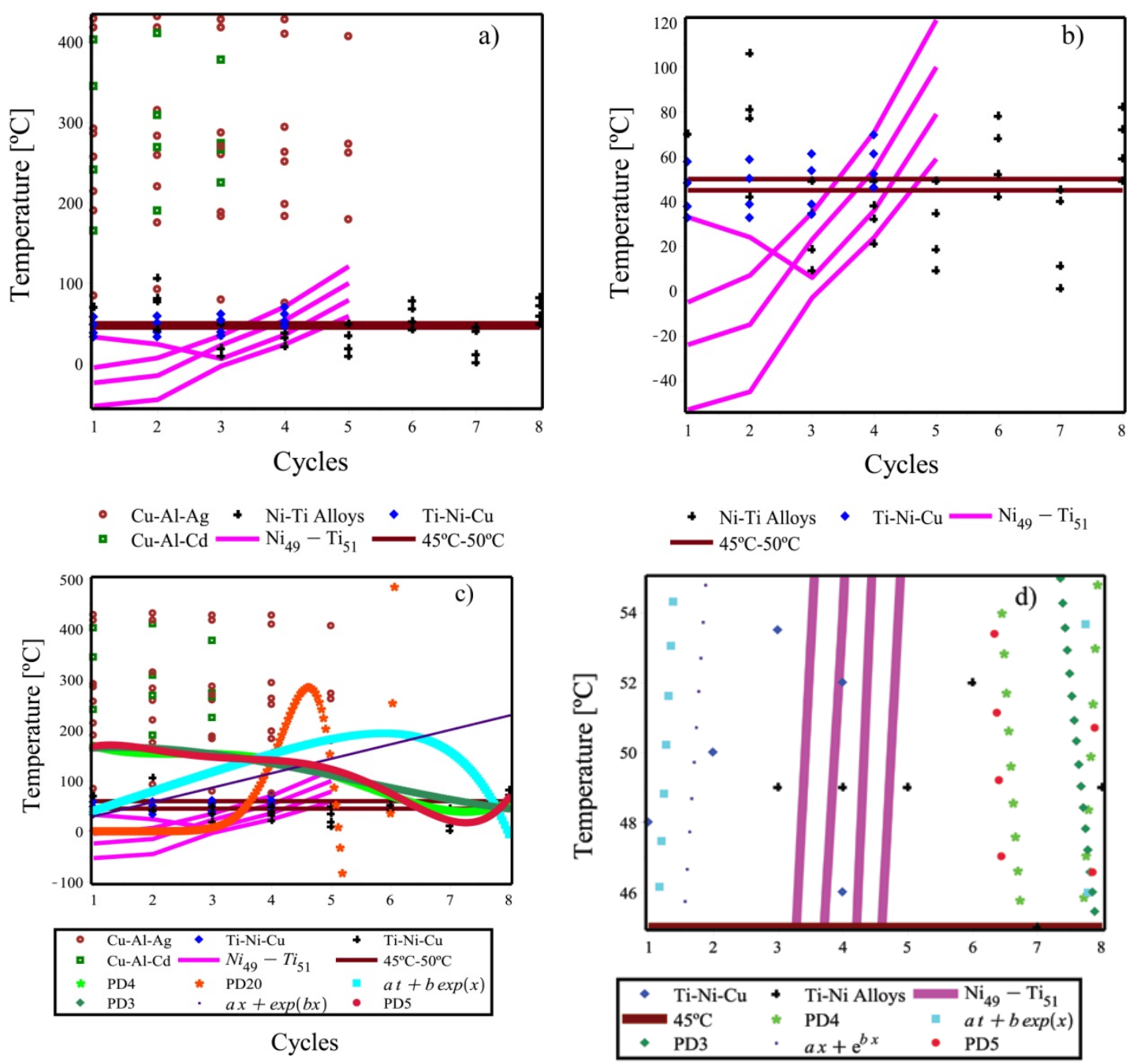

Cycles

Figure 18. Transition Temperatures of SMAs of interest in removal of tumors: a) Ti-Ni-Cu and nitinol alloys, b) enlargement of a); c) fitting curves of data d) expansion of c) showing significant presence of $\mathrm{Ti}-\mathrm{Ni}-\mathrm{Cu}$, nitinol alloys and $\mathrm{Ni}_{49} \mathrm{Ti}_{51}$.

\subsection{Experimental Tests}

The design of the medical instrumentation through the tissue ablation device was constructed with four sharply curved tubular nitinol needles (according with its transformation temperatures) which are deployed from a straight needle after insertion through a stainless steel surgical instrument called trocar $[16,17,38,39]$

Thus, the trocar has the function of deploying needles (called electrode arms), whose ends must reach temperatures of $45^{\circ} \mathrm{C}$ to $50^{\circ} \mathrm{C}$ or higher, during the ablation process of cancerous tissue.

To construct the four electrode arms of $\mathrm{Ni}_{\mathrm{wx}} \mathrm{Ti}_{\mathrm{yz}}$, is necessary to know the mechanical properties of the structures that the alloy has in the temperature range of interest.

When working on the design of devices internal in human tissue, it is needed to control the transformation temperatures to which the changes of shape occur, as well as the loads to which an alloy is going to be submitted. Therefore, in this work we modify the transformation temperatures of nitinol between austenite and matensite phases in a controlled way by the annealing treatment varying temperature and holding time.

There is a difference in the transformation temperatures for the heating of martensite to austenite and the cooling from austenite to martensite, resulting in a delay called "lag" in the transformation or transformation temperature hysteresis. In

Figure 19 a) we can see the hysteresis for some transformation temperatures of nitinol taken from [40]. An enlargement of Figure 3 a) are made to observe in Figure 19 b) that the curve whose data: $A_{f}=71{ }^{\circ} \mathrm{C}, M_{s}=36{ }^{\circ} \mathrm{C}, M_{f}=24{ }^{\circ} \mathrm{C}, A_{s}=54{ }^{\circ} \mathrm{C} \quad$ meets the expectations of ideal temperature of nitinol for burning cancer cells $\left(45^{\circ} \mathrm{C}-50^{\circ} \mathrm{C}\right)$.

The choice of alloy composition was performed based on the previous statistical study, taking into account the transformation temperatures required to burn cancer cells, as well as subsequent experimental study. Thereby, during the performance of experimental tests of nitinol annealing, it 
was necessary to carry the desired austenitic shape to the material for the proper design of the medical device.

In Figure 20 we can observe transition temperatures with different load levels annealed at $500^{\circ} \mathrm{C}$ in a time of $30 \mathrm{~min}$, at cooling and heating rates of $2^{\circ} \mathrm{C} / \mathrm{min}$ in consistency with [8].

The heating curve reflects the martensite-austenite transformation, and the associated temperatures $\mathrm{A}_{\mathrm{s}}, \mathrm{y} \mathrm{A}_{\mathrm{f}}$. In the cooling test, we obtain the transformation temperatures of the martensitic phase, $M_{s}$, and $M_{f}$

In Figure 21 the temperature sensitivity of austenite-martensite transition respect to the annealing temperature in the range $450^{\circ} \mathrm{C}$ to $550^{\circ} \mathrm{C}$ and to the annealing time is reflected.

Figure 22 a) shows the hysteresis loops of the transformation temperatures consistent with those of other authors [9-15]. While in Figure 22 b), as a comparation, it is shown the hysteresis loops of the enlargements of Figs. 19 a) and 22 a) in the interest range of temperatures.

Hysteresis cycles in Figs. 19 and 22, and the hysteresis cycles produced by the transformation temperatures of nitinol alloys subjected to annealing process, allowed to decide on the composition of nitinol used in the construction of the medical device. Thus, the Ni-Ti SMA suited for this application proved to be the $\mathrm{Ni}_{\mathrm{wx}} \mathrm{Ti}_{\mathrm{yz}}$.

In this section, theoretical and experimental results achieved with the tumors remover device adapted to the RC3GL (Figure 5 a)) are presented.

In Figure 23 the thermal profile obtained by the bioheat (12) is shown as well as the profile obtained during one of the experimental tests.

During the process of removal of a tumor, is expected a temperature field in the intervals of $39^{\circ} \mathrm{C}$ to $82^{\circ} \mathrm{C}$ and $361 \mathrm{~K}$ in the electrodes during a period of sixty seconds.

Also, it is expected that the temperature at the tip of an electrode behave as the graph of theoretical model of Figure 23, which, as shown, was achieved experimentally. As it can be seen, the experimental data curve is very close to the theoretical curve, as expected $[16,17,19]$.
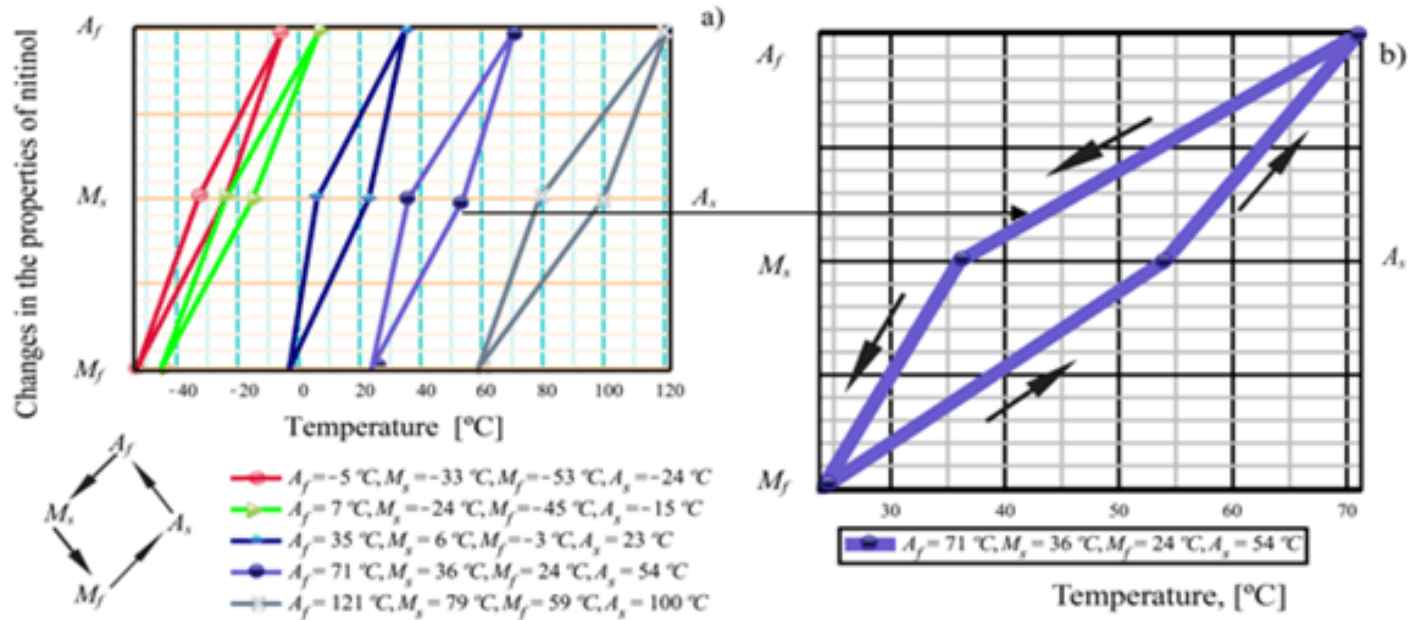

Figure 19. a) Hysteresis for some transformation temperatures of nitinol and b) enlargement of a) for the temperatures of interest. Source [40].
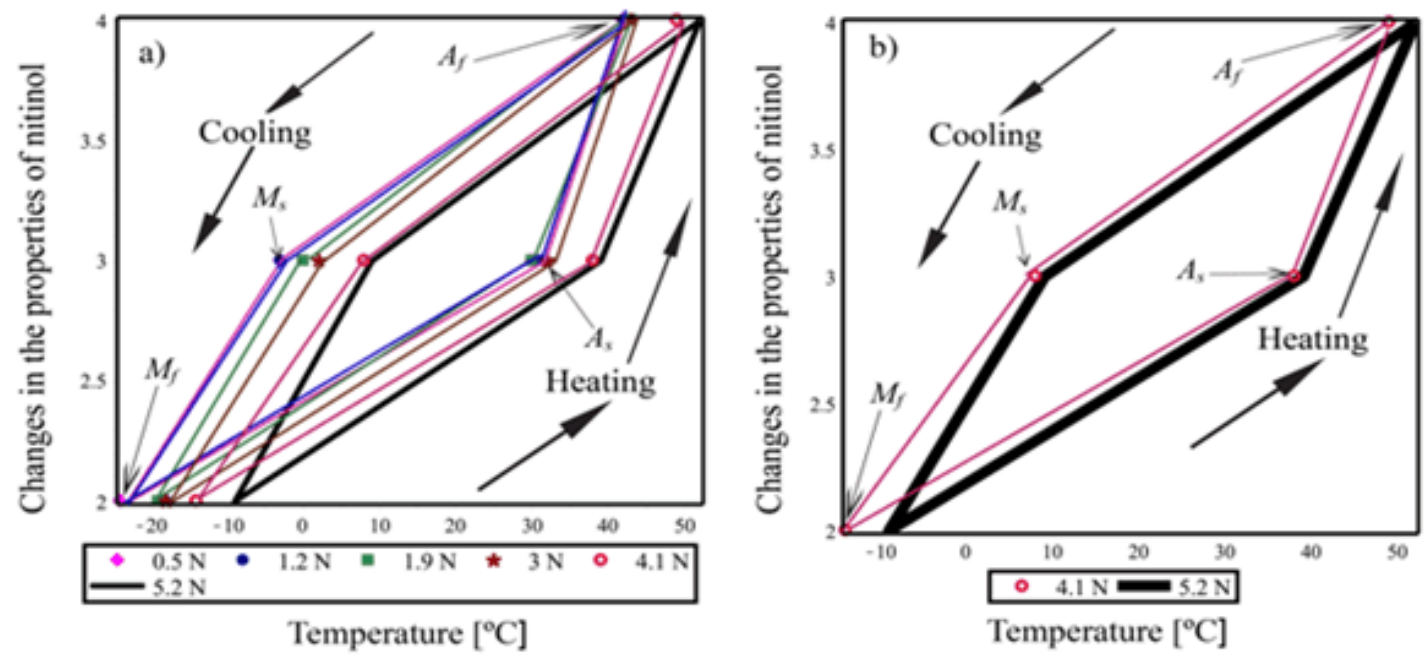

Figure 20. a) transition temperatures with different load levels for wire specimens of Ni-Ti annealed at $500^{\circ} \mathrm{C}$ for 30 minutes, measured with resistivity and DMTA techniques. b) Cycles of importance in the removal of tumors (DMTA technique indicated in cycle with circles). 


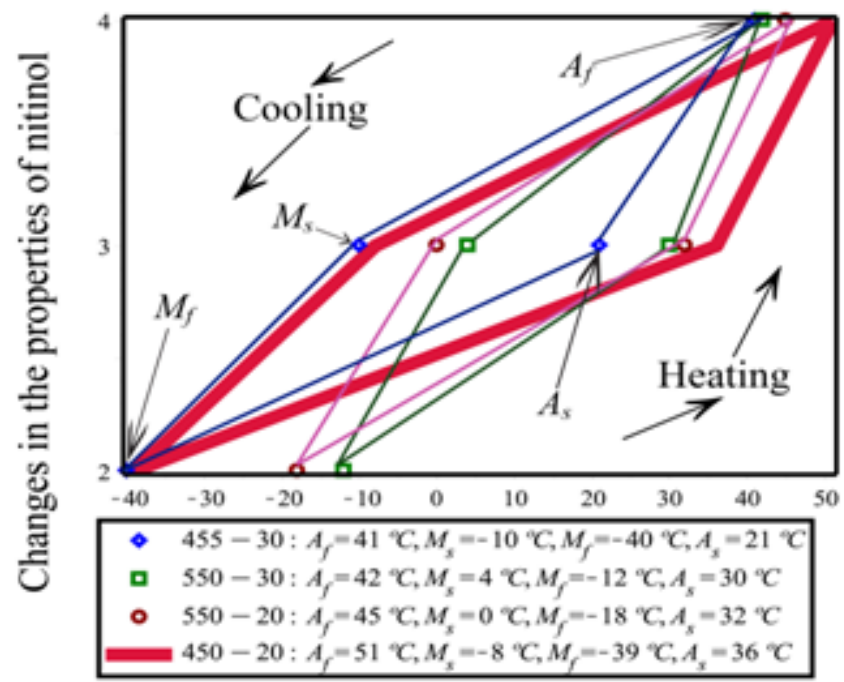

\section{Temperature $\left[{ }^{\circ} \mathrm{C}\right]$}

Figure 21. Transition temperature behavior with respect to annealing temperatures in times of 20 and 30 minutes.

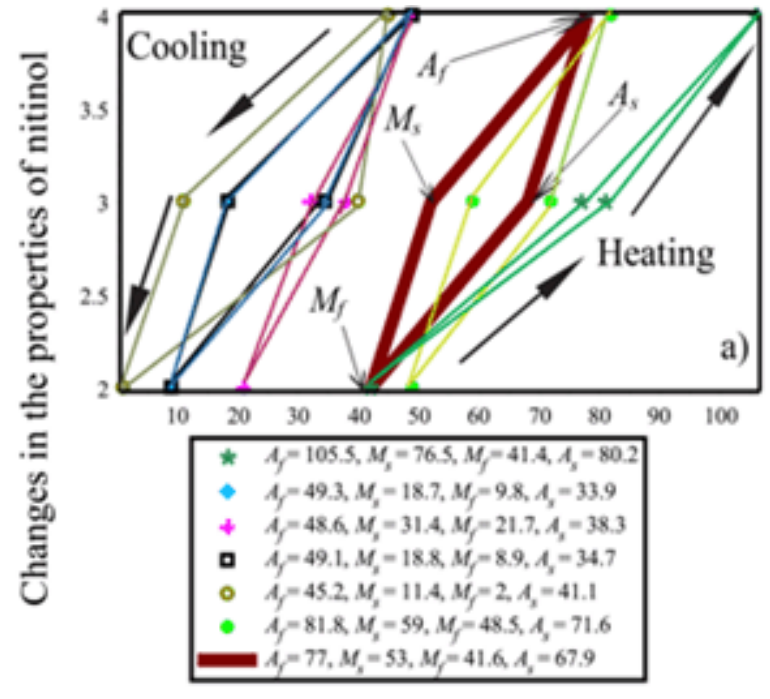

Temperature $\left[{ }^{\circ} \mathrm{C}\right]$

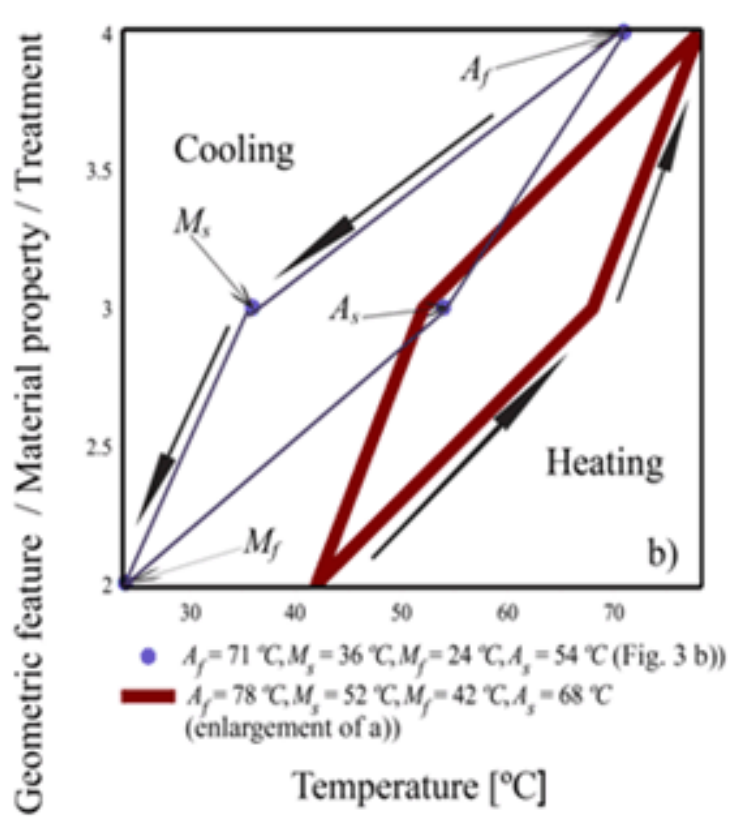

Figure 22. a) Some transition temperatures of SMAs according with various sources [9-15]; as well as b) enlargement of a) showing the transition temperatures of hysteresis in the range of interest consistent with [7] and [15]. 


\section{Conclusions}

The statistical study with SMAs data for obtaining the alloy that meets the requirements of composition and transformation temperatures for the design of a device adapted to a RC3GL for removing tumors; and annealing tests performed on the chosen alloy based on the statistical study; allowed to fulfill the purpose for which it was created the medical application; helping to provide equipment to the medical sector of the State of Chihuahua, where the specialist currently performs the function of tumor ablation manually (patent application by Mexican Institute of Industrial Property number X/a/2014/001576).

The results of the theoretical model for the function to be performed by the device for ablation of cancerous tumors, yields results that closely approximate the experimental tests made with the robot. Thus, model and experiment, allow to obtain the precise thermal profile to remove cancer cells in human organs in eight minutes a session.

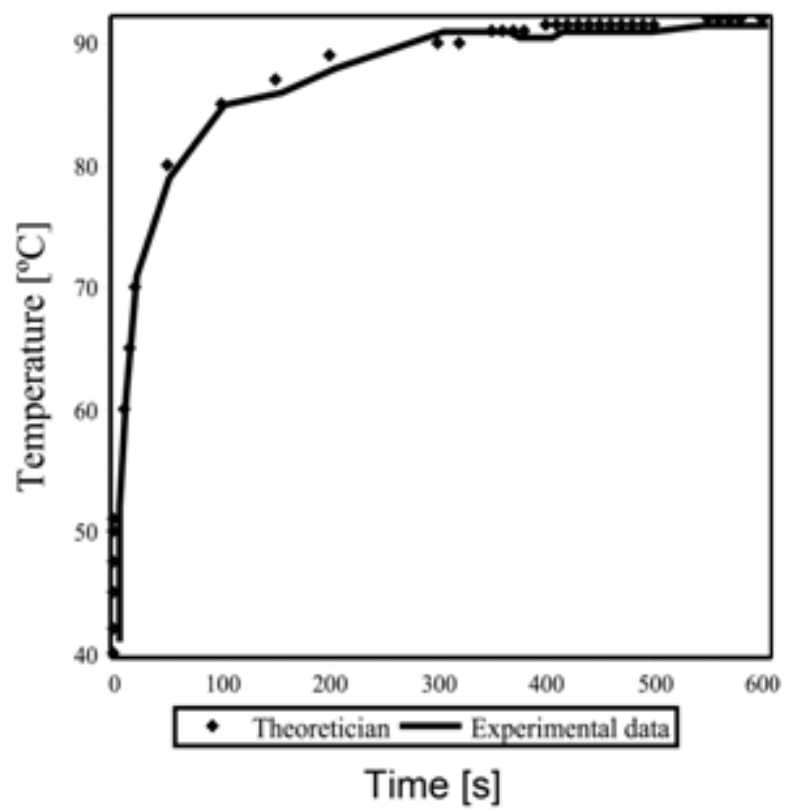

Figure 23. Thermal profile in one of the electrode arms of nitinol during the tumor ablation process.

\section{REFERENCES}

[1] Corral Bustamante, R.L., Núñez Jáquez, E.: Robot Cartesiano de 3 Grados de Libertad. Indautor, México (2010)

[2] M. F. Triola. Estadística, Pearson Educación, México, D.F., 2008.

[3] R. E. Walpole, R.H. Myers, S.L Myers, K. Ye. Probabilidad \& Estadística para ingeniería \& ciencias, Pearson Educación, México, D.F., 2007.

[4] M. Zarinejad, Y. Liu. Shape Memory Alloys: Manufacture, Properties and Applications, Nova Science Publishers, Inc., 2010.
[5] A. Fabregat-Sanjuan, F. Ferrando Piera, S. De la Flor López. Análisis del comportamiento tensión-temperatura para bajos niveles de tensión en Aleaciones con Memoria de Forma TiNiCu, Anales de ingeniería mecánica, Vol. 1 (2012), 1-8.

[6] C.P. Wang, Y. Su, S.Y. Yang, Z. Shi and X. J. Liu. A new type of $\mathrm{Cu}-\mathrm{Al}-\mathrm{Ta}$ shape memory alloy with high martensitic transformation temperature, Vol. 23, No. 2. Smart Mater. Struct. Vol. 23 (2014)

[7] A. Coda, S. Zilio, D. Norwich, F. Sczerzenie. Characterization of Inclusions in VIM/VAR NiTi Alloys, Journal of Materials Engineering and Performance, Vol.21 (2012), 2572-2577.

[8] J. López Longás, J. Canut, R. Ríos, J.A. Puértolas. Biomecánica, Vol. VI (1998), 73-80.

[9] L. C. Brinson. One Dimensional Constitutive Behavior of Shape Memory Alloys: thermo-mechanical derivation with non-constant material functions, Journal of Intelligent Material Systems \& Structures, Vol. 4, No. 2, (1993), 229-242.

[10] X. D. Zhang, C. A. Rogers, C. Liang. Modelling of the Two-Way Shape Memory Effect, Journal of Intelligent Material Systems and Structures, Vol. 8, No. 4, (1997), 353-362.

[11] Z. K. Lu, G. J. Weng. A micromechanical theory for the thermally induced phase transformation in shape memory alloys, Smart Materials and Structures, Vol. 9, No. 5, (2000), 582-591.

[12] M. A. Thrasher, A. R. Shahin, P. H. Meckl, J. D. Jones. Efficiency analysis of shape memory alloy actuators, Smart Materials and Structures, Vol. 3, No. 2, (1994), 226-234.

[13] J. J. Amalraj, A. Bhattacharyya, M. G. Faulkner. Experimental determination of thermal and electrical properties of $\mathrm{Ni}-\mathrm{Ti}$ shape memory wires, Smart Materials and Structures, Vol. 9, No. 5, (2000), 622-631.

[14] G. Wang, M. Shahinpoor. Design, Prototyping and Computer Simulation of A Novel Large Bending Actuator Made with A Shape Memory Alloy Contractile Wire ,Vol. 6, No. 2, (1997), 214-221.

[15] A. Nespoli, S. Besseghini. A complete thermo-mechanical study of a NiTiCu shape memory alloy wire, Journal of Thermal Analysis and Calorimetry, Vol. 103, No. 3, (2011), 821-826.

[16] S. Tungjitkusolmun, S. Tyler Staelin, D. Haemmerich, J. Z. Tsai, H. Cao, J. G. Webster, F. T. Lee, Jr., D.M. Mahvi and V.R. Vorperian, Three-dimensional finite elementanalyses for radio-frequency hepatic tumor ablation, IEEE Trans. Biomed. Eng. Vol. 49, No. 1, (2002), 3-9.

[17] R. L. Corral-Bustamante, E. Siqueiros, J. N. Hernández, J. M. Berlanga, H. Mendoza, J. Salayandía, A. Heiras and M .A. Anchondo, in: Advanced Structured Materials, edited by A. Öchsner and $\mathrm{H}$. Altenbach, volume 40 of Advances in Bio-Mechanical Systems and Materials, chapter 2, Springer International Publishing (2013).

[18] K. Otsuka. Shape Memory Materials, Institute of Materials Science, University of Tsukuba. Cambridge University Press, 1999.

[19] Online Available: https://www.comsol.com/release/4.4 e.g.: COMSOL Multiphysics ${ }^{\circledR}$ Release Highlights Version 4.4 (C) 
2015 by COMSOL Inc. All rights reserve Comsol. Privacy Trademarks RSS Multiphysics Modeling, Finite Element Analysis, and Engineering Simulation Software, Online available from https://www.comsol.com/release/4.4

[20] R. Torres, J. Grau. Introducción a la Mecánica de Fluidos y Transferencia de Calor Con COMSOL Multiphysics, Addlink Media, España, 2007.

[21] R. W. Pryor. Multiphysics modeling using COMSOL ${ }^{\circledR}$ v.4. Mercury Learning and Information, David Pallai, CanadA, 2012.

[22] Online Available: http://alternativeto.net/software/pcb-wizard/?platform=mac e.g.: PCB Wizard Alternatives for Mac OS X AlternativeTo.net, alternativeto.net/software/pcb-wizard/?platform =mac, Online available from http://alternativeto.net/software/pcb-wizard/?platform=mac

[23] Online Available: http://www.solidworks.es/sw/products/3d-cad/packages.htm ?cid=es hp tab products 3d, e.g.: Software de diseño CAD en 3D SOLIDWORKS, Online available from www.solidworks.es/

[24] A. Bejan. Heat Transfer, John Wiley \& Sons, USA, 1993.

[25] R. L. Corral Bustamante. Termofluidos: fundamentos de termodinámica y análisis de fluidos, Editorial Académica Española, Lap Lambert Academic Publishing GmbH \& Co, KG, 2012.

[26] Y. A. Cengel, R. H. Turner. Fundamentals of Thermal-Fluid Sciences, Mcgraw-Hill, New York, 2007.

[27] M. Horsley. Thermofluids, Taylor \& Francis, London, 1996.

[28] F. P. Incropera, D. P. DeWitt. Fundamentos De Transferencia De Calor, Prentice Hall, México, 1999.

[29] D. A. Kaminski, M. K. Jensen. Introduction to Thermal and Fluid Engineering, Wiley, USA, 2005.

[30] G. E. Myers. Analytical Methods in Conduction Heat
Transfer, AMCHT Publications, USA, 1998.

[31] B. Shen, E. S. H. Chu, G. Zhao, et al. PPARgamma inhibits hepatocellular carcinoma metastases in vitro and in mice. Br. J. Cancer, Vol. 106, (2012), 1486-1494.

[32] N.C. van der Voort van Zyp, J. B. Prévost, B. van der Holt. Quality of life after stereotactic radiotherapy for stage I non-small-cell lung cancer, Int. J. Radiat. Oncol. Biol. Phys., Vol. 77, No. 1, 31-7 (2010).

[33] M. D. L. H.. González, C. L. S, P. D. F. Radioterapia. Mini Manuales Prácticos: Oncología, Arán Ediciones, Madrid, 2008

[34] E. C. Halperin, C. A. Perez, L. W. Brady. Principles and Practice of Radiation Oncology, Lippincott Williams \& Wilkins, Philadelphia, 2008.

[35] F. M. Kha. The Physics of Radiation Therapy. Lippincott Williams \& Wilkins, Philadelphia, 2010.

[36] T. S. Lawrence, R. K. T. Haken, A. Giaccia. Principles of radiation oncology. In: DeVita V.T. Jr, Lawrence, T.S., Rosenberg, S.A. (eds.) DeVita, Hellman, and Rosenberg's Cancer: Principles and Practice of Oncology, pp. 307-336. Lippincott Williams \& Wilkins, Philadelphia, 2008.

[37] Y. Martins, R. I. Lederman, C. L. Lowenstein, et al. Increasing response rates from physicians in oncology research: a structured literature review and data from a recent physician survey. Br. J. Cancer. doi (2012). doi:10.1038/bjc.2012.28

[38] D. Tarniță, D.N. Tarniță, N. Bîzdoacă, I. Mîndrilă, M. Vasilescu. Properties and medical applications of shape memory alloys, Romanian Journal of Morphology and Embryology, Vol. 50, No. 1, 15-21, 2009.

[39] Biscarini, G. Mazzolai, A. Tuissi. Enhanced nitinol properties for biomedical applications, Recent patents on biomedical engineering,Vol. 1, No. 3, (2008), 180-196.

[40] Online Available:

Transformation-Temperature-Hysteresis-in-Nitinol-Alloys.ht m, Online availablr from http://jmmedical.com 